\title{
Inflammatory bowel disease and pregnancy: fertility, complications and treatment
}

\author{
Mohammad Fahad Alia, Harry He ${ }^{b}$, David Friedel ${ }^{c}$ \\ Guthrie Cortland Medical Center; Medicine, NYU Winthrop University Hospital, USA
}

\begin{abstract}
Inflammatory bowel disease (IBD) is commonly diagnosed and treated in the young population. Therefore, it is common that women anticipating or undergoing pregnancy will have to cope with the additional burden of their IBD. Pregnancy in an IBD patient also presents challenges for the practitioner, in that the usual diagnostic and therapeutic armamentarium of potential tests and therapies is disrupted. This review covers the implications of IBD for fertility, pregnancy and offspring, and discusses the management of IBD in pregnancy.
\end{abstract}

Keywords Inflammatory bowel disease, pregnancy, ulcerative colitis, Crohn's disease, pregnancy complications

Ann Gastroenterol 2020; 33 (6): 1-12

\section{Introduction}

There are currently an estimated 1-1.3 million people suffering from inflammatory bowel disease (IBD) in the United States [1,2]. Ulcerative colitis (UC) is more common in men and Crohn's disease (CD) is more common in women. Although CD and UC can occur at any age, people are frequently diagnosed between the ages of 15 and 35 years. According to the Olmsted County study, which examined a well-defined US population from 1970-2010, the adjusted annual incidence of CD from 2000-2010 was 10.7 cases per 100,000 person-years, while that of UC was 12.2 per 100,000 person-years. The median age of diagnosis of UC and CD was 34.9 years and 29.5 years, respectively [3]. For women, this age range encompasses the child-bearing years and therefore has implications for fertility, pregnancy, offspring health and treatment.

\section{IBD and effects on fertility}

Fertility rates in women with IBD depend on disease activity and therapeutic strategy. Those with quiescent or

Department of a Gastroenterology and Hepatology, Guthrie Cortland Medical Center (Mohammad Fahad Ali); b Medicine, NYU Winthrop University Hospital (Harry He); 'Gastroenterology, NYU Winthrop University Hospital (David Friedel), USA

Conflict of Interest: None

Correspondence to: Harry He, MD, 222 Station Plaza N, Mineola, NY 11501, USA, e-mail: Harry.he@nyulangone.org

Received 15 June 2020; accepted 27 July 2020; published online 2 October 2020

DOI: https://doi.org/10.20524/aog.2020.0536 medically treated IBD and no prior pelvic surgery have similar infertility rates to the general population, ranging between 5 and 14\% [4-6]. Conversely, active disease can impair fertility, probably via multifactorial mechanisms including pelvic inflammation of the fallopian tubes and ovaries, dyspareunia secondary to perianal disease, and adhesions or scarring from previous surgeries [7]. Voluntary nulliparity due to fear of intimacy and disease transmission to offspring, poor body image (ostomy, perianal disease), and depression are also significant [8].

Pelvic surgery, specifically in UC, can significantly increase female infertility via scarring, adhesions, or injury to the reproductive organs. A meta-analysis of ileal pouch anal anastomosis (IPAA) surgery in UC found a $48 \%$ postoperative infertility rate, 3 times higher than in medically treated patients [9-12]. Delaying abdominal surgeries that spare the pelvis, such as colectomy with ileorectal anastomosis/ subtotal colectomy, rectal stump creation and ileostomy, until childbearing is complete are temporizing measures that may preserve female fertility.

IBD also decreases the efficacy of assisted reproductive technology (ART) treatments in women with infertility. Women with CD should initiate ART treatment before surgery is required for $\mathrm{CD}$. In women with $\mathrm{UC}$ and using ART, the risk of preterm birth is increased 5-fold and thus there should be increased prenatal observation in this population [13].

Data concerning the effects of IBD on male fertility are in shorter supply. Sulfasalazine is known to cause reversible infertility in men, due to dose-dependent oligospermia, reduced sperm motility and altered sperm morphology [14]. Analogously, methotrexate (MTX) may adversely affect sperm morphology, although as with sulfasalazine, such effects are reversible upon medication discontinuation. It is recommended that men stop MTX 3-6 months before conception [15]. 


\section{IBD and effects on preconception and pregnancy}

Women with IBD are more likely to experience pregnancy complications compared to age-matched controls. These include spontaneous abortion, infants small for gestational age (SGA), preterm birth, and labor and delivery complications. They are correlated with disease activity.

Large community-based studies, like the one published by Mahadevan et al in 2007, revealed that women with IBD are more likely to have adverse conception outcomes or pregnancy complications (odds ratios of 1.65 and 1.78 respectively) [16]. Independent predictors of adverse outcomes include a history of surgery for IBD and non-Caucasian ethnicity. Separate studies have further examined the associations between IBD and pregnancy complications such as preterm birth, low birth weight (LBW) and preterm premature rupture of membranes [17-20]. It was shown that disease activity is a strong predictor of these adverse pregnancy outcomes [21-23]. These findings were subsequently confirmed by O'Toole et al in a meta-analysis. Compared with non-diseased controls, data pooled from multiple studies show that women with IBD were at greater risk for preterm birth, SGA, LBW, stillbirth and congenital anomalies [24]. However, the authors did find evidence of publication bias for the link between IBD and congenital anomalies and that association may not be reliable.

Moreover, disease activity at the time of conception influences whether a patient will have an IBD flare during pregnancy. For active UC, roughly $45 \%$ will worsen, a quarter will remain the same and a quarter will improve. In active CD, a third will probably worsen, a third will stay the same (active, stable disease) and one third will improve (remission) [25]. Of women with IBD in remission at the time of conception, $80 \%$ remain in remission and $20 \%$ will experience a disease flare [26-28]. In light of the evidence associating active IBD disease and pregnancy complications, controlling disease activity and suppressing disease flares is the priority in managing IBD in pregnancy. The current Toronto Consensus statements and the European Crohn's and Colitis Organization (ECCO) guidelines were generated accordingly [29,30].

Given the importance of controlling disease activity during conception, preconception counseling becomes crucial. A prospective study of 149 IBD women of childbearing age from 2008-2013 demonstrated that those who received 30 min of preconception IBD point-of-care counseling were more likely to adhere to IBD medications and prenatal vitamins, cease smoking and achieve more controlled perinatal IBD disease activity [31].

Preconception management of women with IBD should include reviewing and optimizing medications, confirming disease remission (fecal calprotectin/colonoscopy) and ensuring standard health care maintenance, such as surveillance colonoscopies, pap smears, vaccinations and blood monitoring, including vitamin D and iron studies.

\section{IBD and mode of delivery}

Cesarean section rates as high as $44 \%$ have been reported in IBD patients [32]. Only a minority of these are likely to be due to true obstetrical indications. A meta-analysis of 6 studies by Cornish et al in 2007 retrospectively examined case-control studies from 1980-2006 and found that the higher rate of cesarean section was significant for CD but not UC [33]. Vaginal delivery has risks for anal sphincter or perineal damage, which lead to worsening perianal disease in CD or pouch dysfunction in patients with IPAA prior to pregnancy. However, some studies show that vaginal delivery is feasible in patients with inactive disease [34-36]. In fact, data suggest that vaginal delivery is of low risk for those with a pouch, with a return to pre-pregnancy function within 6 months [37]. Therefore, delivery by cesarean section is currently recommended for those with active perianal disease at the time of delivery, or with an ileo-anal pouch. Otherwise, the mode of delivery is at the discretion of the obstetrician.

\section{Effects of pregnancy on medical management of IBD patients}

\section{Antibiotics}

Perianal disease and intraabdominal abscesses due to fistulizing $\mathrm{CD}$ are often treated with a combination of metronidazole and ciprofloxacin (FDA category B and category $\mathrm{C}$, respectively). The goal is to provide sufficient anaerobic and gram-negative coverage. Metronidazole, especially for a short course of 5-7 days, is considered safe in pregnancy [38]. Koss et al studied 922 women treated with metronidazole for clinical indications in an urban New York State hospital to compare rates of preterm, birth, LBW or major congenital anomalies $[39,40]$. No association was found between metronidazole treatment and these conditions.

Though fluoroquinolone use was thought to increase the risk of arthropathies in the offspring, studies have not confirmed any associations between ciprofloxacin use and major congenital anomalies, including musculoskeletal complications [41]. A meta-analysis by Bar-Oz et al concluded that fluoroquinolone use during the first trimester of pregnancy does not appear to increase the risk of major malformations, stillbirths, preterm births or LBW [42]. However, given the known potential effect of ciprofloxacin on bone and cartilage, avoidance during pregnancy is recommended [43]. After birth, breastfeeding is discouraged while on either of these antibiotics. Therefore, ECCO guidelines have categorized metronidazole and ciprofloxacin as low risk for short-term use but with limited benefit from long-term treatment [30].

Other antibiotics used in IBD may require alteration in pregnancy. Rifaximin, an FDA category $\mathrm{C}$ medication in pregnancy, has been used to treat pouchitis but has not been well studied in IBD [44]. Amoxicillin/clavulanate is also used to treat pouchitis and is considered an FDA category B medication [45]. As an alternative, penicillins are considered first-line therapy in pregnancy and have not been shown to cause fetal malformations or adverse pregnancy outcomes [31].

Finally, the use of peripartum broad-spectrum antibiotics has been studied in animals. Chang et al published results suggesting that broad-spectrum peripartum antibiotics 
(cefoperazone specifically) promote offspring gut dysbiosis, immune dysfunction and IBD progression. Antibioticperturbed maternal microbiota probably contribute to neonatal gut dysbiosis [46]. More investigation into this question is warranted.

\section{Aminosalicylates (5-ASA)}

The safety of 5-ASA compounds was studied in several trials $[47,48]$. Women taking 5-ASA for IBD do not have a higher incidence of fetal abnormalities than the general population.

The various formulations of mesalamine are generally FDA category B medications, except for Asacol, a category C drug. This label was due to the presence of dibutyl phthalate (DBP) in the coating of Asacol and Asacol HD, which has been associated with urogenital defects in male offspring: nonsignificant adjusted odds ratio (OR) of 1.32 (0.18-9.63) [49]. Notably, these complications only arose with DBP doses of greater than 190 times the human dose in animal studies [50]. Pregnant women should be advised of the potential risk to the fetus and the limitations of the current literature.

Sulfasalazine is a category B drug and is safe to continue peripartum. Pregnant patients treated with sulfasalazine should also have folic acid supplementation at a dose of $1 \mathrm{mg}$ of oral folic acid twice daily in the pre- and perinatal period to avoid fetal neural tube defects [51].

In conclusion, mesalamine and sulfasalazine are safe in pregnancy. A meta-analysis by Rahimi et al, following 2200 pregnant women with IBD, revealed no significant association between the use of mesalamine or sulfasalazine and a greater incidence of congenital malformations, stillbirth, spontaneous abortion, preterm delivery, or LBW [52]. Pregnant patients should be assured of these data.

\section{Immunomodulators}

Previously, thiopurine immunomodulators such as azathioprine (AZA) and mercaptopurine (6-MP) were classified as category D because of the teratogenic effects at high doses observed in animal models. However, the current consensus is that thiopurines are safe during pregnancy [53].

A retrospective study by Francella et al revealed no significant differences in spontaneous abortion, birth defects, congenital malformations, neoplasias or increased infections in patients taking 6-MP compared with controls. 6-MP use appeared to be safe, whether taken before or during pregnancy. Medication discontinuation during those time periods is therefore not indicated [54]. Nevertheless, these medications remain classified as category $\mathrm{D}$.

When the outcomes of 115 pregnancies with paternal exposure to AZA or 6-MP were prospectively analyzed by Hoeltzenbein et al, the rate of major malformations was not increased. There were no birth defects or chromosomal aberrations in the exposed group. However, a higher rate of elective terminations was noted. The authors recommended further prospective studies to explore the possible association with an increased risk of spontaneous abortion [55].

A meta-analysis by Akbari et al answered that question. It included 5 studies comprising women and men exposed to immunomodulators within 3 months of conception and/ or during pregnancy. They analyzed 66 exposed pregnancies with 60 live pregnancies. There was no increased risk of spontaneous abortion, congenital anomalies, LBW or preterm birth (although studies were not adjusted to disease activity) [56]. Casanova et al also showed that the rate of pregnancy complications was similar among the thiopurines (21\%) and non-exposed (28\%) groups (Table 1) [57].

Similarly, the Pregnancy in IBD And Neonatal Outcome (PIANO study) by Mahadevan et al yielded the same results in a prospective setting [16]. PIANO is a prospective registry of pregnancy outcomes in women with IBD, involving 30 IBD centers in the US with over 1500 patients categorized based on drug exposure between conception and delivery. The groups included unexposed patients vs. patients exposed to AZA/6$\mathrm{MP}$, biologics, or any combination of the two. Relative risks of spontaneous abortion, preterm birth, LBW, intrauterine growth restriction (IUGR), cesarean section, neonatal intensive care unit (ICU) stays, and congenital anomalies were not significant.

However, there is evidence that immunomodulators and their metabolites are transferred from mother to fetus [58,59]. DeBoer et al measured thiopurine metabolites 6-thioguaninenucleotides (6-TGN) and 6-methylmercaptopurine (6-MMP) in the red blood cells (RBCs) of mothers and neonates after delivery. 6-TGN concentrations, which correlate with therapeutic doses of immunomodulators, were detected in the RBCs of both the infant and mother. 6-MMP, a marker for immunomodulator hepatotoxicity and myelotoxicity, was not detected in the infants. Therefore, thiopurines should be continued in pregnancy with metabolite monitoring, especially in women with active disease [60].

Jharap et al performed a prospective study examining the effects of pregnancy on thiopurine metabolism and the effect of thiopurine use on exposed fetuses. At birth, all newborns had a normal Apgar score and none had major congenital abnormalities. However, $60 \%$ of the newborns had anemia [61]. Newborns to mothers exposed to thiopurines should have blood counts monitored.

Small studies have examined AZA and 6-MP in lactating women (in both plasma and breast milk). Concentrations of 6-MP in breast milk peaked within the first $4 \mathrm{~h}$ after drug intake with the infant ingesting $<0.008 \mathrm{mg} / \mathrm{kg}$ bodyweight $/ 24 \mathrm{~h}$ or $<1 \%$ maternal dose [62]. Pumping and discarding $4 \mathrm{~h}$ after taking the drug could be a possibility. There was no increase in infections or hospitalizations and all offspring showed ageappropriate mental and physical development [63].

\section{Biologics}

\section{Tumor necrosis factor inhibitors (anti-TNFs)}

Anti-TNFs are generally considered safe during pregnancy and are category B medications. In the PIANO trial to date, more 
Table 1 Summary of studies and evidence of medications

\begin{tabular}{|c|c|c|c|c|c|c|}
\hline Study & Year & Disease & Medication & $\begin{array}{c}\text { \# of exposed } \\
\text { pregnancies/live births }\end{array}$ & Complications & $\begin{array}{c}\text { Congenital } \\
\text { abnormalities }\end{array}$ \\
\hline $\begin{array}{l}\text { Katz/ } \\
\text { IFX Safety } \\
\text { Database [68] }\end{array}$ & 2004 & $\mathrm{CD}$ and $\mathrm{UC}$ & IFX & $131^{1 / 64}$ & $\begin{array}{l}\text { Miscarriages } 15 \% \\
\text { Therapeutic termination } \\
\text { 19\%; Same as general } \\
\text { population }\end{array}$ & 1 \\
\hline Schnitzler [69] & 2011 & $\mathrm{CD}$ and $\mathrm{UC}$ & IFX and ADA & $42 / 32$ & $\begin{array}{l}7 \text { premature deliveries; } \\
6 \text { LBW; } 1 \text { stillbirth and } 1 \\
\text { death; outcomes no different } \\
\text { compared to no or indirect } \\
\text { anti-TNF }\end{array}$ & 1 \\
\hline Johnson [76] & 2011 & $\mathrm{CD}$ & $\mathrm{ADA}$ & $95 / 95$ & $\begin{array}{l}\text { No difference in preterm } \\
\text { delivery, birth weight in } \\
\text { full term infants or serious } \\
\text { infections; }\end{array}$ & $\begin{array}{l}11 \text { major birth defects: } \\
4.5 \% \text { in ADA-exposed } \\
\text { vs. } 5.2 \% \text { in disease- } \\
\text { matched pregnancies } \\
\text { vs. } 6.6 \% \text { in healthy } \\
\text { pregnancies }\end{array}$ \\
\hline $\begin{array}{l}\text { Lichtenstein/ } \\
\text { TREAT [67] }\end{array}$ & 2013 & $\mathrm{CD}$ & IFX & $105 / 80$ & $\begin{array}{l}16.3 \% \text { spontaneous abortion; } \\
\text { clinical condition of infants } \\
\text { born to IFX exposed } \\
\text { women is comparable to } \\
\text { those exposed to other CD } \\
\text { treatments. }\end{array}$ & 1 \\
\hline Casanova [57] & 2013 & $\mathrm{CD}$ and UC & $\begin{array}{l}\text { IFX, ADA and } \\
\text { CZP }\end{array}$ & $66 / 60$ & $\begin{array}{l}\text { The rate of pregnancy } \\
\text { complications was similar } \\
\text { among the anti-TNF ( } 30 \%) \\
\text { vs. thiopurines ( } 21 \%) \text { vs. } \\
\text { non-exposed ( } 28 \%) \text { groups }\end{array}$ & 1 \\
\hline Mahadevan [80] & 2013 & $\mathrm{CD}$ and $\mathrm{UC}$ & $\begin{array}{l}\text { IFX, ADA and } \\
\text { CZP }\end{array}$ & $31 / 33$ & None reported & 0 \\
\hline Lin [95] & 2014 & $\mathrm{CD}$ and $\mathrm{UC}$ & Glucocorticoid & $969^{2}$ & $\begin{array}{l}\text { Glucocorticoid use may } \\
\text { increase risk for preterm } \\
\text { birth, gestational diabetes, } \\
\text { and LBW }\end{array}$ & 82 \\
\hline Zelinkova [81] & 2013 & $\mathrm{CD}$ and $\mathrm{UC}$ & IFX and ADA & $31 / 28$ & 3 miscarriages & 0 \\
\hline Seirafi [75] & 2014 & $\begin{array}{l}\mathrm{CD}, \mathrm{UC} \text { and } \\
\text { undetermined }\end{array}$ & $\begin{array}{l}\text { IFX, ADA and } \\
\text { CZP }\end{array}$ & $133 / 119$ & $\begin{array}{l}\text { Complications in } 35 \% \\
\text { women and } 20 \% \text { newborns; } \\
\text { safety profile similar to } \\
\text { control group }\end{array}$ & 2 \\
\hline Diav-Citrin [72] & 2014 & $\mathrm{CD}$ and $\mathrm{UC}$ & IFX and ADA & $83 / 65$ & $\begin{array}{l}\text { No cases of VATER/ } \\
\text { VACTERL association }\end{array}$ & 3 \\
\hline Clowse [86] & 2015 & $\mathrm{CD}$ & CZP & $192 / 150$ & $\begin{array}{l}32 \text { miscarriages; } 10 \text { induced } \\
\text { abortions }\end{array}$ & 5 \\
\hline De Lima [74] & 2016 & $\mathrm{CD}$ and $\mathrm{UC}$ & IFX and ADA & $106 / 83$ & $\begin{array}{l}\text { No difference in IBD relapse } \\
\text { rate between women in deep } \\
\text { remission who stopped IFX } \\
\text { and those who did not in } \\
\text { after week } 22 \text {. Similar birth } \\
\text { outcomes }\end{array}$ & 0 \\
\hline Naureckas [90] & 2016 & $\mathrm{CD}$ and $\mathrm{UC}$ & UST & $87 / 57$ & $\begin{array}{l}16 \text { spontaneous abortions, } \\
14 \text { elective terminations, } \\
\text { comparable to general } \\
\text { population rates }\end{array}$ & 1 \\
\hline
\end{tabular}


Table 1 (Continued)

\begin{tabular}{|c|c|c|c|c|c|c|}
\hline Study & Year & Disease & Medication & $\begin{array}{l}\text { \# of exposed } \\
\text { pregnancies/live births }\end{array}$ & Complications & $\begin{array}{c}\text { Congenital } \\
\text { abnormalities }\end{array}$ \\
\hline Mahadevan [88] & 2017 & $\mathrm{CD}$ and $\mathrm{UC}$ & VDZ & $24 / 11$ & $\begin{array}{l}\text { One corpus callosum } \\
\text { agenesis abnormality } \\
\text { reported in a patient with } \\
\text { extensive obstetric history }\end{array}$ & 1 \\
\hline Chaparro [71] & 2018 & $\mathrm{CD}$ and UC & IFX & $841^{3}$ & $\begin{array}{l}\text { No increase in infection } \\
\text { rates in childhood in } \\
\text { children exposed to } \\
\text { anti-TNFs }\end{array}$ & \\
\hline Mahadevan [93] & 2018 & $\mathrm{UC}$ & TOF & $25 / 15^{4}$ & $\begin{array}{l}\text { No fetal deaths, neonatal } \\
\text { deaths. Adverse events } \\
\text { analogous to general } \\
\text { population }\end{array}$ & 0 \\
\hline $\begin{array}{l}\text { Bar-Gil } \\
\text { Shitrit [89] }\end{array}$ & 2019 & $\mathrm{CD}$ and UC & VDZ & $24 / 15$ & $\begin{array}{l}\text { Higher abortion rate in } \\
\text { pregnant women taking } \\
\text { VDZ compared to women } \\
\text { taking ADA, IFX which may } \\
\text { be confounded by baseline } \\
\text { disease activity. Rates of IBD } \\
\text { flares and steroid usage was } \\
\text { significantly decreased }\end{array}$ & 0 \\
\hline \multicolumn{7}{|c|}{${ }^{1}$ data obtained from 96 of 131 patients } \\
\hline \multicolumn{7}{|c|}{${ }^{2}$ Study of infants after birth whose mothers required glucocorticoids perinatally } \\
\hline \multicolumn{7}{|c|}{${ }^{3}$ Study of 841 children, half with mothers exposed to anti-TNFs and half without } \\
\hline \multicolumn{7}{|c|}{${ }^{4} 6$ patients were lost to follow up; pregnancy and birth status is unknown for them } \\
\hline \multicolumn{7}{|c|}{$\begin{array}{l}C D \text {, Crohn's disease; UC, ulcerative colitis; IFX, infliximab; ADA, adalimumab; CZP, certolizumab pegol; anti-TNF, tumor necrosis factor inhibitor; SGA, small } \\
\text { for gestational age; } L B W \text {, low birth weight }\end{array}$} \\
\hline
\end{tabular}

than 500 women have been exposed to anti-TNF medications during pregnancy, including approximately 260 to infliximab (IFX), 150 to adalimumab (ADA), 65 to certolizumab pegol (CZP), and 29 to a combination of agents. No increased rates of congenital anomalies were observed compared with the unexposed IBD cohort.

Similarly, a systematic review by Nielsen et al of more than 1500 anti-TNF-exposed pregnancies and a metaanalysis by Narula et al, comprising more than 1200 participants, found no pattern of adverse pregnancy outcomes (preterm delivery, abortion, LBW), congenital anomalies or immunosuppression $[64,65]$.

Additional investigations studying anti-TNFs during pregnancy include the TREAT registry, which examined 117 pregnancies in CD patients on IFX and other therapies, the IFX Safety Database, which followed 96 women with CD and rheumatoid arthritis, and a large single-center study with 212 women on IFX and ADA (Table 1) [66-69]. In all these studies, there were no differences in the rates of miscarriage, neonatal complications, fetal malformation, live births, miscarriages, therapeutic terminations or general pregnancy outcomes between exposed and non-exposed individuals.

The PIANO registry, however, indicated that combination therapy with anti-TNFs and thiopurines may be associated with 2.4-fold greater odds of preterm birth and 1.7-fold greater odds of general pregnancy complications and delayed infant infections: relative risk 1.35 (1.01-1.80). Julsgaard et al also demonstrated a nearly 3 -fold elevated risk of infection in infants born to women who were on this combination therapy during pregnancy compared to those on anti-TNF therapy alone [70]. However, this finding was challenged in the multicenter European TEDDY study, where 841 children were studied; approximately half had anti-TNF exposure (with or without thiopurine combination therapy) in utero and the other half did not. The 2 groups were compared and the incidence of severe infections were found to be similar (Table 1) [71]. Because of these conflicting data, the current guidelines state that anti-TNFs should be continued, especially in patients with more severe disease activity, as maintaining remission is paramount. [29].

Research has also been focused on the impact of antiTNFs on fetuses (Table 1) [72-76]. As depicted in Fig. 1, immunoglobulins, and particularly all 4 subclasses of IgG (1-4), are detectable in the umbilical circulation. IgG transferred via the placenta persists longer in the newborn than in the mother, with a half-life of 48.4 days [77-79]. Anti-TNFs was found to actively traverse the placenta via the FcRn receptor, starting as early as the $2^{\text {nd }}$ trimester, with the majority occurring in the $3^{\text {rd }}$ trimester. Drug levels of IFX, ADA and CZP measured in a study by Mahadevan et al in mothers at birth, cord blood, infants, and then followed monthly in the infant until they were undetectable, showed wide ranges for IFX and ADA (2.9-39.5 $\mu \mathrm{g} / \mathrm{mL}$ and $4.28-17.7 \mu \mathrm{g} / \mathrm{mL}$ respectively), along with significant median cord-to-maternal drug level ratios (Table 1) [80]. The median level of IFX in the cord was $160 \%$ that of the mother and the median level of ADA in the cord 


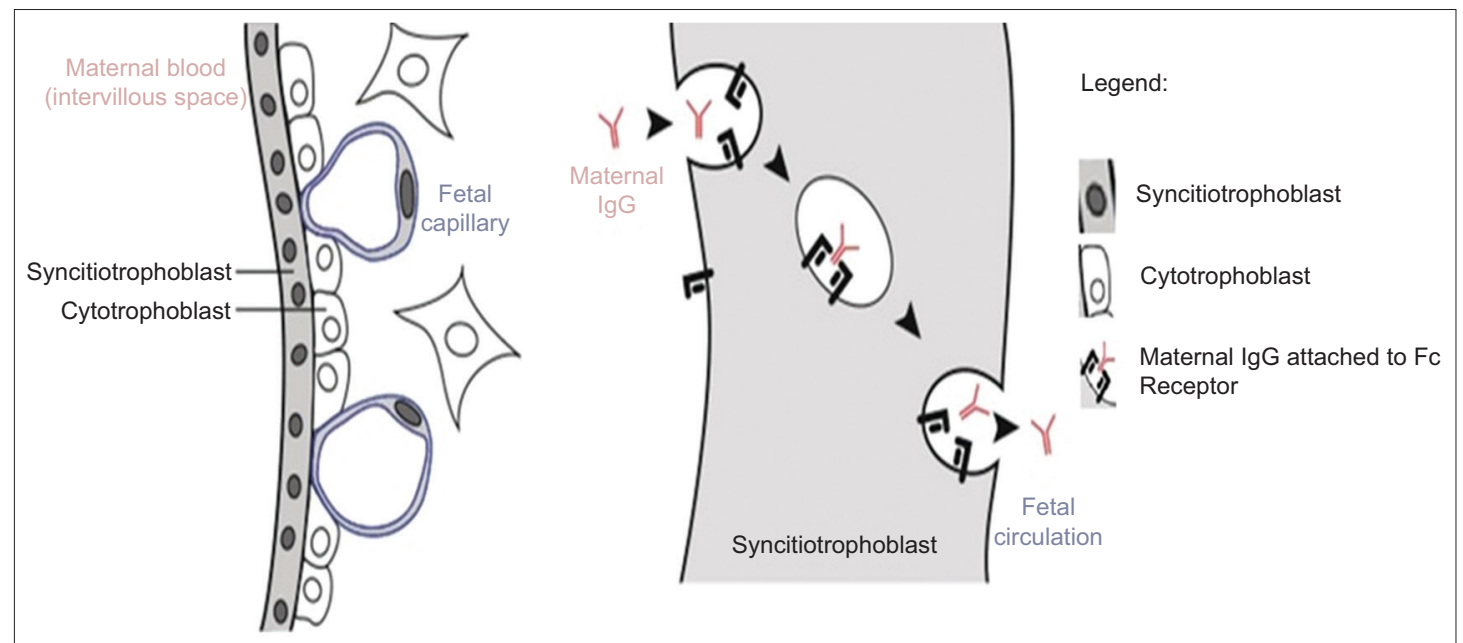

Figure 1 Active transplacental transport of immunoglobulin G (IgG). Reproduced with permission, Oxford University Press (http:// creativecommons.org/licenses/by-nc/4.0), Hazes JMW. Rheumatoid Am J Reprod Immunol 2011;50:1955-1968

was $153 \%$ that of the mother. IFX levels were detectable for 2-7 months in the infant. ADA levels were detectable for 3 months. CZP had the lowest level of placental transfer, based on levels measured in cords and infants at birth, probably because it lacks an Fc portion. The median level of CZP in the cord was $3.9 \%$ that of the mother.

Subsequently, Julsgaard et al, in a prospective study, measured the umbilical cord and infant blood concentrations of IFX and ADA in women exposed to anti-TNF agents during pregnancy. They found that the IFX and ADA levels in the cord and infant blood were greater than that in the mother, as reflected by the median ratio of infant-to-mother drug concentration at birth (1.21 for ADA, $95 \%$ confidence interval [CI] 0.94-1.49; 1.97 for IFX, 95\%CI 1.50-2.43). Interestingly, IFX was cleared more slowly than ADA from the infants and drugs were detected in infants until 12 months of age. The significance of this is not yet known [70].

The PIANO registry data did not show any association between biologic exposure in the third trimester and preterm birth, infections after 1 year of age, or disease activity in the third trimester or 4 months post-partum. Third trimester antiTNF exposure did not detrimentally affect infant growth rate, immune development, number of infections or achievement of developmental milestones. Zelinkova et al also published data comprising 31 pregnancies in 28 women with IBD, observing the consequences of stopping anti-TNFs in the $3^{\text {rd }}$ trimester (Table 1) [81]. All patients who stopped taking IFX (12 of $17,71 \%$ ) before gestational week 30 remained in remission, whereas 2 of 11 patients taking ADA who discontinued treatment before gestational week 30 had relapses of IBD. Of the 28 live births, there was 1 miscarriage in the IFX cohort and 2 miscarriages in the ADA cohort. There were no congenital malformations. Of these patients, $22 \%(5 / 23)$ had a flare or required therapy alteration postpartum. The investigators concluded that discontinuation of anti-TNF therapy appears to be safe for pregnant women with quiescent IBD.

Given that anti-TNF medications are transferred from mother to infant and that holding the medications in the $3^{\text {rd }}$ trimester is found to be relatively safe, women in sustained remission should consider $3^{\text {rd }}$ trimester anti-TNF dosing adjustments to minimize neonatal exposure [15]. Serum trough concentrations enable therapeutic drug monitoring and should help guide dosing in the late $2^{\text {nd }}$ or early $3^{\text {rd }}$ trimester of pregnancy.

Finally, extrapolating from the ongoing PIANO registry and controlling for drug exposure, breastfeeding in mothers on biologic therapy has not been associated with infection risk, abnormal height or weight, or deviations in achievement of developmental milestones. While disease activity and immunomodulator use has been inversely associated with breastfeeding, there is no such correlation with biologics. Beaulieu et al also analyzed PIANO, looking at serum samples collected from infants at least 7 months old for antibody titers to Haemophilus influenzae B or tetanus toxin in mothers exposed to biologic therapy and compared them to infants born to unexposed mothers [82]. They concluded that the use of biologic therapy does not affect the infant's response to vaccines.

A study by Benhorin revealed that, although IFX levels in breast milk increased to $101 \mathrm{ng} / \mathrm{mL}$ within 2-3 days of the infusion, these levels were roughly $1 / 200^{\text {th }}$ of the level in blood (i.e., $0.5 \%$ plasma concentration) [83]. Likewise, ADA levels in breast milk were roughly $1 / 200^{\text {th }}$ of the level in blood $[84,85]$. Since there is minimal if any placental transfer of CZP, none was detected in breastmilk (Table 1) [86].

In conclusion, anti-TNF agents are safe to use during pregnancy to induce and sustain disease control. Based on available safety data, there is no increased risk of congenital anomalies among infants exposed to these medications [87]. Consensus guidelines support continuing anti-TNFs throughout pregnancy. The decision to hold anti-TNFs in situations such as strong patient preferences to limit fetal exposure should be made on an individual case-by-case basis with extensive counseling. Holding the medication should only be considered in patients with a low risk of relapse: sustained symptomatic remission for at least a year before conception, 
no evidence of active disease on imaging or endoscopy, documented therapeutic drug levels, no prior dose escalation, no intestinal resections, and no hospitalizations within the last 36 months for IBD flare. Guidelines suggest administering the last dose of anti-TNFs at 22-24 weeks gestation. With regard to postnatal care, these immunosuppressants are detectable in infants up to 6 months after birth. Therefore, current guidelines recommend delaying live vaccines for 6-12 months, with antiTNF drug levels measured and drug clearance documented to help inform decisions $[29,30]$.

\section{Anti-integrins}

Vedolizumab (VDZ) is a monoclonal antibody that provides gut-selective anti-inflammatory activity by blocking the $\alpha 4 \beta 7$ integrin. Vedolizumab is an FDA category B medication. Available data concerning its safety in pregnancy are limited. Mahadevan et al reported 27 pregnancies in 24 VDZ-treated females as well as 19 pregnant partners of males with IBD treated with VDZ across 6 studies (Table 1) [88]. Analysis of the female group showed a correlation between the severity of disease activity and pre-term live birth or spontaneous abortions. The data did not associate VDZ with any new safety concerns. Analysis of the partner group showed a similar trend. It seems that VDZ displays a similar pregnancy safety profile to that of anti-TNF medications and that the use of VDZ is not associated with more adverse outcomes, though this study was limited by small sample sizes and incomplete follow up.

Shitrit et al prospectively followed 330 pregnancies, of which 20 were in the setting of VDZ use at least 3 months before conception and continued throughout the third trimester (Table 1) [89]. They were compared to patients treated with TNF inhibitors, as well as those treated with 5-ASA and thiopurines. The abortion rate was significantly higher than that of the other groups. A possible confounder to this is the fact that patients on VDZ have already failed one or more biologics and therefore have more refractory and severe disease at baseline, which independently leads to worse pregnancy outcomes. Conversely, the rate of flares and corticosteroid usage in the VDZ group was significantly lower.

Based on the available evidence, VDZ appears safe to use in pregnancy and adverse pregnancy outcomes correlate with baseline IBD disease activity. These studies are currently limited by small sample sizes and larger studies with longer follow-ups are needed.

\section{Anti-interleukin (IL) 12/23 agents}

Ustekinumab (UST) is a humanized IgG1 that binds and inhibits IL-12 and IL-23 and is an FDA category B medication. Data regarding the safety of these drugs in pregnant IBD patients have been extrapolated from studies in patients with psoriasis. Naureckas et al studied pregnancy outcomes in pregnant women with psoriasis (plaque psoriasis or psoriatic arthritis) exposed to UST (Table 1) [90]. Eighty-seven pregnancy reports were identified, predominantly in patients with plaque psoriasis. Average maternal age was 31 years. Most pregnancies $(57 / 87 ; 65.5 \%)$ resulted in live births. There was one congenital anomaly (1.2\%), 16 spontaneous abortions (18.4\%), and 14 elective terminations (16.1\%). In 16 of 87 pregnancies there was exposure to UST in all 3 trimesters whereas 37 reported exposure in the first trimester. In both these instances, the rates of spontaneous abortions and elective terminations were comparable to those reported in the general population (15-20\%).

Similarly, Schaufelberger et al studied pregnancies with maternal use of UST from 4 phase 2 and 3 plaque psoriasis studies (ACCEPT and PHOENIX trials) [91]: 981 female patients received $\geq 1$ dose of UST and 29 pregnancies were reported. The mean maternal age was 30 years and the mean duration of UST exposure prior to the reported pregnancy was $72 \pm 61$ weeks. Pregnancy outcomes were reported for 26 of 29 pregnancies, including 14 (54\%) live births, 5 (19\%) spontaneous abortions and $7(27 \%)$ elective abortions. All 5 spontaneous abortions occurred in the $1^{\text {st }}$ trimester. Neonatal outcomes were generally healthy. Longer duration of UST exposure prior to the reported pregnancy was not associated with adverse outcomes. Even though the limited available data suggest that UST exposure may not impact pregnancy outcomes, the evidence is weak, and it is not recommended throughout pregnancy.

In a prospective multicenter study by Matro et al of women with IBD and their infants, the authors analyzed collected breast milk samples from patients receiving biologic therapy including UST, IFX, ADA, CZP, and natalizumab [92]. They reported low concentrations of these medications in the breast milk samples, with levels of UST ranging between 0.72 and $1.57 \mu \mathrm{g} / \mathrm{mL}$. Breastfed infants of these mothers being treated with biologics and/or immunomodulators had infection risks and rates of milestone achievement comparable to those of non-breastfed infants and infants not exposed to these drugs. Maternal use of biologic therapy appears compatible with breastfeeding.

\section{Janus kinase inhibitor}

Outcome data following tofacitinib, a Janus kinase inhibitor, for UC in pregnancy are ongoing but limited. It is an FDA category $\mathrm{C}$ medication. Mahadevan et al recently reported outcomes of pregnancies with maternal and paternal exposure to tofacitinib in 5 UC interventional studies (Table 1)[93]. Eleven cases of maternal and 14 cases of paternal exposure to tofacitinib prepartum and peripartum were identified among 301 women of childbearing age. The pregnancy outcomes were 15 healthy newborns, 2 spontaneous abortions, and 2 medical terminations. No fetal deaths, neonatal deaths, or congenital malformations were noted. The adverse events were analogous to those reported for tofacitinib use in populations with rheumatologic disorders and to the background risks in the general population. It should be noted that tofacitinib was found to be teratogenic in animal models, with malformations such as omphalocele, ventricular septal defects and cranial abnormalities, though this was only observed at drug exposure levels of 70-140 times the recommended human drug dosing [94]. Given the lack of robust evidence and the small 
sample sizes in available studies, general recommendations at the current time suggest avoiding use in pregnant women until additional information is available.

\section{MTX}

MTX is absolutely contraindicated in pregnancy (FDA Class X). It is an abortifacient and teratogen and postconception use has been clearly linked to abortions and major birth defects [15]. Women of childbearing age should be on 1-2 forms of contraception and should wait at least 3-6 months after stopping MTX before attempting conception. MTX is also contraindicated in breastfeeding. Although excreted at levels $<10 \%$ of maternal plasma concentration, its long half-life allows accumulation in neonatal tissue.

Table 2 summarizes the current recommendations for each class of medication.

\section{Glucocorticoids}

Glucocorticoids are FDA Class C. Data from the PIANO registry indicates that corticosteroid use during pregnancy is associated with preterm birth (OR 1.8, 95\%CI 1.0-1.31), LBW (OR 2.8, 95\%CI 1.3-6.1), and gestational diabetes (OR 2.8, 95\%CI 1.3-6.0). There were no associations with infection, congenital malformation, cleft palate or developmental delay. Adjusted analysis found no difference in spontaneous abortions, IUGR, cesarean section, congenital malformations, neonatal ICU stays, or infections between exposed and unexposed patients.

Corticosteroids may be used to treat disease flares, despite their association with an increased risk of pregnancy complications. Their use during pregnancy should be restricted to the lowest effective dose for the shortest duration. In a separate retrospective study, these risks were not seen specifically with budesonide. Prednisone and budesonide are both compatible with breastfeeding. Their drug levels in breast milk are less than $0.05 \%$ of maternal dose (Table 1) [95].

\section{Management of an IBD flare during pregnancy}

Prior to diagnosing a flare during pregnancy, infection should always be ruled out with stool studies (including Clostridium difficile toxin polymerase chain reaction). Since erythrocyte sedimentation ratio and C-reactive protein are

Table 2 Summary of inflammatory bowel disease medications and recommendations in pregnancy

\begin{tabular}{|c|c|c|c|c|}
\hline Medication & $\begin{array}{l}\text { FDA } \\
\text { Category }\end{array}$ & $\begin{array}{l}\text { Recommendations for women in conception \& } \\
\text { pregnancy }\end{array}$ & $\begin{array}{l}\text { Breast milk drug } \\
\text { concentration }\end{array}$ & $\begin{array}{l}\text { Breastfeeding } \\
\text { Recommendations }\end{array}$ \\
\hline MTX & $\mathrm{X}$ & $\begin{array}{l}\text { Contraindicated; Teratogen and abortifacient. Stop } \\
\text { 3-6 months before conception }\end{array}$ & $\begin{array}{l}\text { Low: }<10 \% \text { of plasma } \\
\text { concentration }\end{array}$ & Contraindicated \\
\hline AZA/6-MP & $\mathrm{D}$ & $\begin{array}{l}\text { Monotherapy: may continue during conception } \\
\text { and pregnancy; } \\
\text { Combination therapy with biologic: consider } \\
\text { stopping thiopurine before conception in } \\
\text { quiescent disease }\end{array}$ & $\begin{array}{l}\text { Clinically insignificant: } \\
\text { peak excretion } 4 \mathrm{~h} \text { after } \\
\text { ingestion }\end{array}$ & $\begin{array}{l}\text { Compatible: wait } 4 \mathrm{~h} \text { after } \\
\text { ingestion if possible }\end{array}$ \\
\hline IFX & B & $\begin{array}{l}\text { Possible risk of infant infection when combined } \\
\text { with thiopurine. Give last dose in the third } \\
\text { trimester (week } 30-32 \text { ). Consider measuring } \\
\text { trough levels in second trimester. }\end{array}$ & $\begin{array}{l}\text { Clinically insignificant: } \\
0.5 \% \text { of plasma } \\
\text { concentration }(\mathrm{ng} / \mathrm{mL}) \\
\text { peak excretion } 24-96 \mathrm{~h} \\
\text { after infusion }\end{array}$ & $\begin{array}{l}\text { Compatible: doubtful oral } \\
\text { bioavailability in infant }\end{array}$ \\
\hline ADA & $\mathrm{B}$ & $\begin{array}{l}\text { Possible risk of infant infection when combined } \\
\text { with thiopurine. Give last dose in the } 3^{\text {rd }} \text { trimester } \\
\text { (week } 36-38 \text { ). Consider measuring trough levels in } \\
\text { second trimester. }\end{array}$ & $\begin{array}{l}\text { Clinically insignificant: } \\
<1 \% \text { of plasma } \\
\text { concentration }(\mathrm{ng} / \mathrm{mL}) \\
\text { peak excretion } 1-6 \mathrm{~d} \\
\text { after injection }\end{array}$ & $\begin{array}{l}\text { Compatible: doubtful oral } \\
\text { bioavailability in infant }\end{array}$ \\
\hline $\mathrm{CZP}$ & $\mathrm{B}$ & $\begin{array}{l}\text { May continue throughout pregnancy without } \\
\text { dosing adjustment. }\end{array}$ & $\begin{array}{l}\text { Clinically insignificant: } \\
\text { peak excretion } 12-48 \mathrm{~h} \\
\text { after injection }\end{array}$ & $\begin{array}{l}\text { Compatible: doubtful oral } \\
\text { bioavailability in infant }\end{array}$ \\
\hline VDZ & B & Give last dose in the third trimester (week 30-32) & Unknown & $\begin{array}{l}\text { Compatible: doubtful oral } \\
\text { bioavailability in infant }\end{array}$ \\
\hline UST & B & Limited human data & $\begin{array}{l}\text { Clinically insignificant: } \\
\text { peak excretion } 24 \mathrm{~h} \text { after } \\
\text { injection }\end{array}$ & $\begin{array}{l}\text { Compatible: doubtful oral } \\
\text { bioavailability in infant }\end{array}$ \\
\hline
\end{tabular}

MTX, methotrexate; AZA, azathioprine; 6-MP, 6-mercaptopurine; IFX, infliximab; ADA, adalimumab; CZP, certolizumab pegol; VDZ, vedolizumab; UST, ustekinumab; TOF, tofacitinib 
usually elevated in pregnancy, fecal calprotectin should be monitored and trended to rule in a flare. The gastroenterologist should ensure that there is a baseline fecal calprotectin measured before conception. Magnetic resonance imaging is the imaging modality of choice (gadolinium contraindicated in the $1^{\text {st }}$ trimester), but ultrasound can also be used. Flexible sigmoidoscopy without sedation can be considered (in any semester) to rule out cytomegalovirus, for which pregnant patients are at higher risk. Deep vein thrombosis prophylaxis is also important. Indications for surgery are similar to those in non-pregnant patients ( $2^{\text {nd }}$ trimester is optimal).

There is a general reluctance to perform radiation-based procedures and endoscopies during pregnancy, because of concerns about sedation and hemodynamic fluctuations with the latter that may be deleterious for the fetus. In general, all endoscopic procedures should only be performed if the potential findings would change perinatal management and preferably in the second semester. Flexible sigmoidoscopies are preferred over pan-colonoscopy. Less invasive monitoring, such as inflammatory markers and fecal calprotectin, is preferred.

For targeted treatment, mesalamine can be initiated at any time during pregnancy for patients with UC. Biologics can be initiated in the first or second trimester with modification of dosage and frequency as necessary. New AZA and 6-MP should be avoided in the first trimester. If necessary, glucocorticoids can be used cautiously at this time in disease flares, as inducing remission and suppressing disease activity are of utmost importance [29].

In rare cases, pregnant women with severely active IBD might require surgery to treat life-threatening conditions refractory to medical therapy, such as toxic megacolon, intestinal obstruction and significant gastrointestinal hemorrhage. Colectomy during the second and third trimester is low-risk without significant adverse pregnancy outcomes [96]. If necessary, mothers with less than 28 weeks gestation can opt for the Turnbull-Blowhole colostomy for colonic decompression and ileal diversion with delayed restorative proctocolectomy and IPAA. On the other hand, for patients with more than 28 weeks gestation, a synchronous cesarean section with subtotal colectomy is a feasible alternative [97]. Surgery for perineal fistulas is usually postponed until after delivery. Non-obstetric surgeries are generally well tolerated and should ideally be performed in the second trimester [98].

A systematic review of 3 databases of women who underwent IBD surgery during pregnancy noted that there were no maternal or fetal mortalities, but there was an almost $50 \%$ preterm delivery rate [99]. Approximately $18 \%$ of cases were de novo presentations and the most common reasons were refractory UC and small bowel perforations.

\section{Concluding remarks}

Many women of child-bearing age are newly diagnosed with IBD every year. The addition of biologics to the armamentarium of 5-ASA and immunomodulators has provided more treatment options, but their impact on pregnancy outcomes (from the perspective of both mother and child) have yet to be fully understood. However, the growing body of research into this field has revealed some important insights. Firstly, maintaining control of IBD before and during pregnancy is paramount. Active disease increases the risk of complications such as stillbirth, premature delivery, and LBW. In addition to appropriate medical therapy, high quality prenatal education and counseling are crucial. Secondly, current data suggest that biologics can be used safely in pregnant women. Although medications like IFX and ADA are IgG1 antibodies that can cross the placenta and have been detected in breastmilk and infants post-delivery, no obvious harm has been reported. More data are required for the anti-integrins and IL-12/23 agents before definitive recommendations can be made. Immunomodulators should be continued given the risk of flare on discontinuation. However, one must consider the possibility of adverse outcomes (e.g., preterm birth) when biologics are used in combination with anti-TNF agents. 5-ASA appear to be safe in pregnancy and breast feeding. Finally, the value of a detailed discussion with the patient and shared decision making cannot be emphasized enough because all decisions should be taken with the overall risks vs. benefits kept in mind.

\section{Future directions}

As we delve deeper into the molecular and genetic mechanisms underlying the pathogenesis of IBD and develop novel treatments, e.g., Janus kinase inhibitors, anti-SMAD 7 oligonucleotides and cell-based therapies, more therapeutic options will become available to pregnant women with CD and UC. Additionally, our growing insight into the seminal role of the gut microbiome in the pathogenesis of IBD will enable the development of new efficacious medications that can be tailored to the specific individual.

\section{Acknowledgments}

We would like to thank NYU Winthrop University Hospital and the Department of Gastroenterology, Hepatology, and Nutrition for supporting our research in this review article.

\section{References}

1. Kappelman MD, Rifas-Shiman SL, Kleinman K, et al. The prevalence and geographic distribution of Crohn's disease and ulcerative colitis in the United States. Clin Gastroenterol Hepatol 2007;5:1424-1429.

2. Loftus EV Jr. Clinical epidemiology of inflammatory bowel disease: Incidence, prevalence, and environmental influences. Gastroenterology 2004;126:1504-1517.

3. Shivashankar R, Tremaine WJ, Harmsen WS, Loftus EV Jr. Incidence and prevalence of Crohn's disease and ulcerative colitis 
in Olmsted County, Minnesota from 1970 through 2010. Clin Gastroenterol Hepatol 2017;15:857-863.

4. Ananthakrishnan AN. Pregnancy, conception, and 'childbirth. In: Ananthakrishnan AN, Xavier RJ, Podolsky DK. Inflammatory Bowel Diseases: A Clinician's Guide. John Wiley \& Sons Ltd, 2017: pp. 199-207.

5. McConnell RA, Mahadevan U. Pregnancy and the patient with inflammatory bowel disease: fertility, treatment, delivery, and complications. Gastroenterol Clin North Am 2016;45:285-301.

6. Tavernier N, Fumery M, Peyrin-Biroulet L, Colombel JF, GowerRousseau C. Systematic review: fertility in non-surgically treated inflammatory bowel disease. Aliment Pharmacol Ther 2013;38:847-853.

7. Van Assche G, Dignass A, Reinisch W, et al; European Crohn's and Colitis Organisation (ECCO). The second European evidencebased Consensus on the diagnosis and management of Crohn's disease: Special situations. J Crohns Colitis 2010;4:63-101.

8. Timmer A, Bauer A, Dignass A, Rogler G. Sexual function in persons with inflammatory bowel disease: a survey with matched controls. Clin Gastroenterol Hepatol 2007;5:87-94.

9. Ørding Olsen K, Juul S, Berndtsson I, Oresland T, Laurberg S. Ulcerative colitis: female fecundity before diagnosis, during disease, and after surgery compared with a population sample. Gastroenterology 2002;122:15-19.

10. Waljee A, Waljee J, Morris AM, Higgins PD. Threefold increased risk of infertility: a meta-analysis of infertility after ileal pouch anal anastomosis in ulcerative colitis. Gut 2006;55:1575-1580.

11. Rajaratnam SG, Eglinton TW, Hider P, Fearnhead NS. Impact of ileal pouch-anal anastomosis on female fertility: meta-analysis and systematic review. Int J Colorectal Dis 2011;26:1365-1374.

12. Hudson M, Flett G, Sinclair TS, Brunt PW, Templeton A, Mowat NA. Fertility and pregnancy in inflammatory bowel disease. Int J Gynaecol Obstet 1997;58:229-237.

13. Nørgård BM, Larsen PV, Fedder J, de Silva PS, Larsen MD, Friedman S. Live birth and adverse birth outcomes in women with ulcerative colitis and Crohn's disease receiving assisted reproduction: a 20-year nationwide cohort study. Gut 2016;65:767-776.

14. O’Moráin C, Smethurst P, Doré CJ, Levi AJ. Reversible male infertility due to sulphasalazine: studies in man and rat. Gut 1984;25:1078-1084.

15. Levy RA, de Jesús GR, de Jesús NR, Klumb EM. Critical review of the current recommendations for the treatment of systemic inflammatory rheumatic diseases during pregnancy and lactation. Autoimmun Rev 2016;15:955-963.

16. Mahadevan U, Sandborn WJ, Li DK, Hakimian S, Kane S, Corley DA. Pregnancy outcomes in women with inflammatory bowel disease: a large community-based study from Northern California. Gastroenterology 2007;133:1106-1112.

17. Bush MC, Patel S, Lapinski RH, Stone JL. Perinatal outcomes in inflammatory bowel disease. J Matern Fetal Neonatal Med 2004;15:237-241.

18. Nørgård B, Hundborg HH, Jacobsen BA, Nielsen GL, Fonager K. Disease activity in pregnant women with Crohn's disease and birth outcomes: a regional Danish cohort study. Am J Gastroenterol 2007;102:1947-1954.

19. Reddy D, Murphy SJ, Kane SV, Present DH, Kornbluth AA. Relapses of inflammatory bowel disease during pregnancy: inhospital management and birth outcomes. Am J Gastroenterol 2008;103:1203-1209.

20. Bröms G, Granath F, Linder M, Stephansson O, Elmberg M, Kieler H. Birth outcomes in women with inflammatory bowel disease: effects of disease activity and drug exposure. Inflamm Bowel Dis 2014;20:1091-1098.

21. Morales M, Berney T, Jenny A, Morel P, Extermann P. 'Crohn's disease as a risk factor for the outcome of pregnancy. Hepatogastroenterology 2000;47:1595-1598.
22. Nielsen OH, Andreasson B, Bondesen S, Jarnum S. Pregnancy in ulcerative colitis. Scand J Gastroenterol 1983;18:735-742.

23. Bortoli A, Pedersen N, Duricova D, et al; European Crohn-Colitis Organisation (ECCO) Study Group of Epidemiologic Committee (EpiCom). Pregnancy outcome in inflammatory bowel disease: prospective European case-control ECCO-EpiCom study, 20032006. Aliment Pharmacol Ther 2011;34:724-734.

24. O'Toole A, Nwanne O, Tomlinson T. Inflammatory bowel disease increases risk of adverse pregnancy outcomes: a meta-analysis. Dig Dis Sci 2015;60:2750-2761.

25. Miller JP. Inflammatory bowel disease in pregnancy: a review. $J R$ Soc Med 1986;79:221-225.

26. Abhyankar A, Ham M, Moss AC. Meta-analysis: the impact of disease activity at conception on disease activity during pregnancy in patients with inflammatory bowel disease. Aliment Pharmacol Ther 2013;38:460-466.

27. Khosla R, Willoughby CP, Jewell DP. Crohn's disease and pregnancy. Gut 1984;25:52-56.

28. Beaulieu DB, Kane S. Inflammatory bowel disease in pregnancy. World J Gastroenterol 2011;17:2696-2701.

29. Nguyen GC, Seow CH, Maxwell C, et al; Canadian Association of Gastroenterology. The Toronto Consensus Statements for the Management of Inflammatory Bowel Disease in Pregnancy. Gastroenterology 2016;150:734-757.

30. van der Woude CJ, Ardizzone S, Bengtson MB, et al; European Crohn's and Colitis Organization. The second European evidencedbased consensus on reproduction and pregnancy in inflammatory bowel disease. J'Crohns Colitis 2015;9:107-124.

31. de Lima A, Zelinkova Z, Mulders AG, van der Woude CJ. Preconception care reduces relapse of inflammatory bowel disease during pregnancy. Clin Gastroenterol Hepatol 2016;14:1285-1292.

32. Mahadevan U, Martin C, Sandler R, et al. A multi-center national prospective study of pregnancy and neonatal outcomes in women with inflammatory bowel disease exposed to immunomodulators and biologic therapy. Gastroenterology 2009;5(Suppl 1):A88.

33. Cornish J, Tan E, Teare J, et al. A meta-analysis on the influence of inflammatory bowel disease on pregnancy. Gut 2007;56:830-837.

34. Brandt LJ, Estabrook SG, Reinus JF. Results of a survey to evaluate whether vaginal delivery and episiotomy lead to perineal involvement in women with Crohn's disease. Am J Gastroenterol 1995;90:1918-1922.

35. Beniada A, Benoist G, Maurel J, Dreyfus M. [Inflammatory bowel disease and pregnancy: report of 76 cases and review of the literature]. J Gynecol Obstet Biol Reprod (Paris) 2005;34:581-588.

36. Ilnyckyji A, Blanchard JF, Rawsthorne P, Bernstein CN. Perianal Crohn's disease and pregnancy: role of the mode of delivery. Am J Gastroenterol 1999;94:3274-3278.

37. Hahnloser D, Pemberton JH, Wolff BG, et al. Pregnancy and delivery before and after ileal pouch-anal anastomosis for inflammatory bowel disease: immediate and long-term consequences and outcomes. Dis Colon Rectum 2004;47:1127-1135.

38. Mylonas I. Antibiotic chemotherapy during pregnancy and lactation period: aspects for consideration. Arch Gynecol Obstet 2011;283:7-18

39. Koss CA, Baras DC, Lane SD, et al. Investigation of metronidazole use during pregnancy and adverse birth outcomes. Antimicrob Agents Chemother 2012;56:4800-4805.

40. Moskovitz DN, Bodian C, Chapman ML, et al. The effect on the fetus of medications used to treat pregnant inflammatory boweldisease patients. Am J Gastroenterol 2004;99:656-661.

41. Nahum GG, Uhl K, Kennedy DL. Antibiotic use in pregnancy and lactation: what is and is not known about teratogenic and toxic risks. Obstet Gynecol 2006;107:1120-1138.

42. Bar-Oz B, Moretti ME, Boskovic R, 'O'Brien L, Koren G. The safety of quinolones-a meta-analysis of pregnancy outcomes. Eur $J$ 
Obstet Gynecol Reprod Biol 2009;143:75-78.

43. Nielsen OH, Maxwell C, Hendel J. IBD medications during pregnancy and lactation. Nat Rev Gastroenterol Hepatol 2014;11:116-127.

44. Isaacs KL, Sandler RS, Abreu M, et al; Crohn's and Colitis Foundation of America Clinical Alliance. Rifaximin for the treatment of active pouchitis: a randomized, double-blind, placebo-controlled pilot study. Inflamm Bowel Dis 2007;13:1250-1255.

45. Hashash JG, Kane S. Pregnancy and inflammatory bowel disease. Gastroenterol Hepatol 2015;11:96-102.

46. Miyoshi J, Bobe AM, Miyoshi S, et al. Peripartum antibiotics promote gut dysbiosis, loss of immune tolerance, and inflammatory bowel disease in genetically prone offspring. Cell Rep 2017;20:491-504.

47. Diav-Citrin O, Park YH, Veerasuntharam G, et al. The safety of mesalamine in human pregnancy: a prospective controlled cohort study. Gastroenterology 1998;114:23-28.

48. Marteau P, Tennenbaum R, Elefant E, Lémann M, Cosnes J. Foetal outcome in women with inflammatory bowel disease treated during pregnancy with oral mesalazine microgranules. Aliment Pharmacol Ther 1998;12:1101-1108.

49. Singh A, Martin CF, Kane SV, et al. Is asacol use associated with congenital anomalies? Results from a nationwide prospective pregnancy registry. Gastroenterology 2013;144(Suppl 1):S-379.

50. Mahaboob Basha P, Radha MJ. Gestational di-n-butyl phthalate exposure induced developmental and teratogenic anomalies in rats: a multigenerational assessment. Environ Sci Pollut Res Int 2017;24:4537-4551.

51. Baggott JE, Morgan SL, Ha T, Vaughn WH, Hine RJ. Inhibition of folate-dependent enzymes by non-steroidal anti-inflammatory drugs. Biochem J 1992;282(Pt 1):197-202.

52. Rahimi R, Nikfar S, Rezaie A, Abdollahi M. Pregnancy outcome in women with inflammatory bowel disease following exposure to 5-aminosalicylic acid drugs: a meta-analysis. Reprod Toxicol 2008;25:271-275.

53. Polifka JE, Friedman JM. Teratogen update: azathioprine and 6-mercaptopurine. Teratology 2002;65:240-261.

54. Francella A, Dyan A, Bodian C, Rubin P, Chapman M, Present DH. The safety of 6-mercaptopurine for childbearing patients with inflammatory bowel disease: a retrospective cohort study. Gastroenterology 2003;124:9-17.

55. Hoeltzenbein M, Weber-Schoendorfer C, Borisch C, Allignol A, Meister R, Schaefer C. Pregnancy outcome after paternal exposure to azathioprine/6-mercaptopurine. Reprod Toxicol 2012;34:364-369.

56. Akbari M, Shah S, Velayos FS, Mahadevan U, Cheifetz AS. Systematic review and meta-analysis on the effects of thiopurines on birth outcomes from female and male patients with inflammatory bowel disease. Inflamm Bowel Dis 2013;19:15-22.

57. Casanova MJ, Chaparro M, Domènech E, et al. Safety of thiopurines and anti-TNF- $\alpha$ drugs during pregnancy in patients with inflammatory bowel disease. Am J Gastroenterol 2013;108:433-440.

58. Chaparro M, GisbertJP.Transplacentaltransferofimmunosuppressants and biologics used for the treatment of inflammatory bowel disease. Curr Pharm Biotechnol 2011;12:765-773.

59. Zimm S, Collins JM, Riccardi R, et al. Variable bioavailability of oral mercaptopurine. Is maintenance chemotherapy in acute lymphoblastic leukemia being optimally delivered? N Engl J Med 1983;308:1005-1009.

60. de Boer NK, Jarbandhan SV, de Graaf P, Mulder CJ, van Elburg RM, van Bodegraven AA. Azathioprine use during pregnancy: unexpected intrauterine exposure to metabolites. Am J Gastroenterol 2006;101:1390-1392.

61. Jharap B, de Boer NK, Stokkers P, et al; Dutch initiative on Crohn and Colitis. Intrauterine exposure and pharmacology of conventional thiopurine therapy in pregnant patients with inflammatory bowel disease. Gut 2014;63:451-457.
62. Christensen LA, Dahlerup JF, Nielsen MJ, Fallingborg JF, Schmiegelow K. Azathioprine treatment during lactation. Aliment Pharmacol Ther 2008;28:1209-1213.

63. Angelberger S, Reinisch W, Messerschmidt A, et al. Long-term follow-up of babies exposed to azathioprine in utero and via breastfeeding. J Crohns Colitis 2011;5:95-100.

64. Nielsen OH, Loftus EV Jr, Jess T. Safety of TNF- $\alpha$ inhibitors during IBD pregnancy: a systematic review. BMC Med 2013;11:174.

65. Narula N, Al-Dabbagh R, Dhillon A, Sands BE, Marshall JK. Anti-TNF $\alpha$ therapies are safe during pregnancy in women with inflammatory bowel disease: a systematic review and metaanalysis. Inflamm Bowel Dis 2014;20:1862-1869.

66. Lichtenstein G, Cohen RD, Feagan BG, et al. Safety of infliximab in 'Crohn's disease: data from the 5000-patient TREAT registry. Gastroenterology 2004;126:A54.

67. Lichtenstein G, Feagan B, Cohen R, et al. Pregnancy outcomes in patients with Crohn's disease treated with infliximab: results from the TREAT registry. Am J Gastroenterol 2013;108:S521.

68. Katz JA, Antoni C, Keenan GF, Smith DE, Jacobs SJ, Lichtenstein GR. Outcome of pregnancy in women receiving infliximab for the treatment of 'Crohn's disease and rheumatoid arthritis. Am J Gastroenterol 2004;99:2385-2392.

69. Schnitzler F, Fidder H, Ferrante M, et al. Outcome of pregnancy in women with inflammatory bowel disease treated with antitumor necrosis factor therapy. Inflamm Bowel Dis 2011;17:1846-1854.

70. Julsgaard M, Christensen LA, Gibson PR, et al. Concentrations of adalimumab and infliximab in mothers and newborns, and effects on infection. Gastroenterology 2016;151:110-119.

71. Chaparro M, Verreth A, Lobaton $T$, et al. Long-term safety of in utero exposure to anti-TNF $\alpha$ drugs for the treatment of inflammatory bowel disease: results from the multicenter European TEDDY study. Am J Gastroenterol 2018;113:396-403.

72. Diav-Citrin O, Otcheretianski-Volodarsky A, Shechtman S, Ornoy A. Pregnancy outcome following gestational exposure to TNF-alpha-inhibitors: a prospective, comparative, observational study. Reprod Toxicol 2014;43:78-84.

73. Clowse ME, Wolf DC, Förger F, et al. Pregnancy outcomes in subjects exposed to certolizumabpegol. J Rheumatol 2015;42:2270-2278.

74. de Lima A, Zelinkova Z, van der Ent C, Steegers EA, van der Woude CJ. Tailored anti-TNF therapy during pregnancy in patients with IBD: maternal and fetal safety. Gut 2016;65:1261-1268.

75. Seirafi M, de Vroey B, Amiot A, et al. Factors associated with pregnancy outcome in anti-TNF treated women with inflammatory bowel disease. Aliment Pharmacol Ther 2014;40:363-373.

76. Johnson D, Luo Y, Jones KL, Chambers C. Pregnancy outcomes in women exposed to adalimumab: an update on the autoimmune diseases in pregnancy project. Arthritis Rheum 2011;63:S730-S731.

77. Malek A, Sager R, Schneider H. Maternal-fetal transport of immunoglobulin $\mathrm{G}$ and its subclasses during the third trimester of human pregnancy. Am J Reprod Immunol 1994;32:8-14.

78. Sarvas H, Seppälä I, Kurikka S, Siegberg R, Mäkelä O. Half-life of the maternal IgG1 allotype in infants. J Clin Immunol 1993;13:145-151.

79. Hazes JM, Coulie PG, Geenen V, et al. Rheumatoid arthritis and pregnancy: evolution of disease activity and pathophysiological considerations for drug use. Rheumatology (Oxford) 2011;50:1955-1968.

80. Mahadevan U, Wolf DC, Dubinsky M, et al. Placental transfer of anti-tumor necrosis factor agents in pregnant patients with inflammatory bowel disease. Clin Gastroenterol Hepatol 2013;11:286-292.

81. Zelinkova Z, van der Ent C, Bruin KF, et al; Dutch Delta IBD Group. Effects of discontinuing anti-tumor necrosis factor therapy during pregnancy on the course of inflammatory bowel disease and neonatal exposure. Clin Gastroenterol Hepatol 2013;11:318-321.

82. Beaulieu DB, Ananthakrishnan AN, Martin C, Cohen RD, Kane SV, Mahadevan U. Use of biologic therapy by pregnant women with 
inflammatory bowel disease does not affect infant response to vaccines. Clin Gastroenterol Hepatol 2018;16:99-105.

83. Ben-Horin S, Yavzori M, Kopylov U, et al. Detection of infliximab in breast milk of nursing mothers with inflammatory bowel disease. J Crohns Colitis 2011;5:555-558.

84. Ben-Horin S, Yavzori M, Katz L, et al. Adalimumab level in breast milk of a nursing mother. Clin Gastroenterol Hepatol 2010;8:475-476.

85. Fritzsche J, Pilch A, Mury D, Schaefer C, Weber-Schoendorfer C. Infliximab and adalimumab use during breastfeeding. J Clin Gastroenterol 2012;46:718-719.

86. Clowse ME, Förger F, Hwang C, et al. Minimal to no transfer of certolizumab pegol into breast milk: results from CRADLE, a prospective, postmarketing, multicentre, pharmacokinetic study. Ann Rheum Dis 2017;76:1890-1896.

87. McConnell RA, Mahadevan U. Use of immunomodulators and biologics before, during, and after pregnancy. Inflamm Bowel Dis 2016;22:213-223.

88. Mahadevan U, Vermeire S, Lasch K, et al. Vedolizumab exposure in pregnancy: outcomes from clinical studies in inflammatory bowel disease. Aliment Pharmacol Ther 2017;45:941-950.

89. Bar-Gil Shitrit A, Ben Ya'acov A, Livovsky DM, et al. Exposure to Vedolizumab in IBD pregnant women appears of low risk for mother and neonate: a first prospective comparison study. Am J Gastroenterol 2019;114:1172-1175.

90. Naureckas S, Slater J, Gearhart N, et al. Pregnancy outcomes in women with psoriasis and psoriatic arthritis exposed to ustekinumab. J Am Acad Dermatol 2016;74(Suppl 1):AB264.

91. Cather JC, Rahawi KW, Schaufelberger BW, Chan D, Horn EJ, Goyal K. Pregnancy outcomes in women exposed to ustekinumab in the psoriasis clinical development program. J Am Acad Dermatol
2014;70(Suppl 1):AB178.

92. Matro R, Martin CF, Wolf D, Shah SA, Mahadevan U. Exposure concentrations of infants breastfed by women receiving biologic therapies for inflammatory bowel diseases and effects of breastfeeding on infections and development. Gastroenterology 2018;155:696-704.

93. Mahadevan U, Dubinsky MC, Su C, et al. Outcomes of pregnancies with maternal/paternal exposure in the Tofacitinib safety databases for ulcerative colitis. Inflamm Bowel Dis 2018;24:2494-2500.

94. Pfizer_Inc. Xeljanz, Highlights of Prescribing Information. 2018. Available from: http://labeling.pfizer.com/ShowLabeling. aspx?id=959\#section-8.1 [Accessed 15 September 2020]

95. Lin K, Martin CF, Dassopoulos T, et al. Pregnancy outcomes amongst mothers with inflammatory bowel disease exposed to systemic corticosteroids: results of the PIANO registry. Gastroenterology 2014;146(Suppl 1):S1.

96. Dozois EJ, Wolff BG, Tremaine WJ, et al. Maternal and fetal outcome after colectomy for fulminant ulcerative colitis during pregnancy: case series and literature review. Dis Colon Rectum 2006;49:64-73.

97. Haq AI, Sahai A, Hallwoth S, Rampton DS, Dorudi S. Synchronous colectomy and caesarean section for fulminant ulcerative colitis: case report and review of the literature. Int $J$ Colorectal Dis 2006;21:465-469.

98. Kilpatrick CC, Monga M. Approach to the acute abdomen in pregnancy. Obstet Gynecol Clin North Am 2007;34:389-402.

99. Killeen S, Gunn J, Hartley J. Surgical management of complicated and medically refractory inflammatory bowel disease during pregnancy. Colorectal Dis 2017;19:123-138. 